\title{
S. Y. AGNON: DO FOLCLORE À FICÇÃO
}

\section{S. Y. AGNON: FROM FOLKLORE TO FICTION}

Nancy Rozenchan*

\begin{abstract}
Resumo: A atuação do autor israelense Shmuel Yossef Agnon, agraciado com o Prêmio Nobel de literatura em 1966, pode ser definida pelo seu perfil único de produção literária que incluiu obras que vão do folclore à ficção e que se estendeu por seis décadas. Tendo vivido por vários anos em diversas cidades em três países, absorveu delas elementos variados que deram os tons judaico e universal à sua obra. Todavia, estas influências não se manifestaram em geral de imediato em seus escritos; destarte, o desconcerto entre tom, temática e abordagem com a época e local em que foram produzidas é um dos aspectos muitos específicos dos seus livros. Destacam-se, aqui, alguns dos traços perceptíveis da escrita dos períodos da Galícia, da Palestina sob Mandato Britânico, da Alemanha e de Israel.
\end{abstract}

Palavras-chave: S. Y. Agnon. Literatura hebraica. Literatura israelense.

\begin{abstract}
The performance of Israeli author Shmuel Yossef Agnon, awarded the Nobel Prize for Literature in 1966, can be defined by his unique profile of literary production that included works ranging from folklore to fiction and which spanned over six decades. Having lived for several years in various cities in three countries, he absorbed from them varied elements that gave the Jewish and universal tones to his work. These influences, however, did not appear soon in his writings; the disconcert between tone, theme and approach to the time and place in which they were produced is one of the many specific aspects of his books. Some of the perceptible features of the Galicia, Palestine under British Mandate, Germany and Israel periods writing are highlighted here.
\end{abstract}

Keywords: S. Y. Agnon. Hebrew literature. Israeli literature.

Talvez se possa afirmar que a ficção hebraica é mais privilegiada que a de outras línguas. A par das virtudes encontradas em muitas outras literaturas, a que é escrita na língua da Bíblia conta com uma fortuna cultural que data de milênios, é produzida em um país que se renovou e, de forma incessante, dá voz a todas as camadas e etnias culturais que nos séculos XX e XXI se enraizaram em Israel. Com tudo isto, faz-se necessário mencionar que esta ficção originouse fora do país. Foi na Europa Central e no Leste europeu que esta literatura deu os seus primeiros passos antes que uma plêiade de autores se decidisse a unir o seu destino ao do país que se prenunciava. De uma parte ou de outra da Europa, do mundo eslavo, do Império AustroHúngaro ou da Alemanha eles brotaram, absorveram, cresceram e, em seguida, se assentaram no que iria se tornar o Estado de Israel. Em meio às diversas ondas imigratórias iniciais que adentraram a Palestina sob domínio do Império Otomano e posteriormente sob Mandato Britânico encontravam-se ficcionistas, poetas e ensaístas.

O escritor israelense Shmuel Yossef Agnon (Shai Agnon, originalmente Shmuel Yossef Czaczkes) ganhador do Prêmio Nobel de Literatura em 1966, nascido em 1887 em Buczacz, na Galícia Oriental, então parte do Império Austro-Húngaro, hoje Ucrânia, e falecido em 1970, em Jerusalém, foi o escritor que mais marcou a literatura hebraica contemporânea, tanto em vida como após a morte, um verdadeiro romancista fundador. Que o digam Amós Oz, A. B. Yehoshua e David Grossman, alguns de seus mais conhecidos discípulos e suas respectivas obras.

A carreira de Agnon, quase toda em hebraico, prolongou-se por seis décadas, foi desenvolvida em sítios diferentes, e nestes foi marcada por fatores variados e, com estes, deixou suas chancelas no pensamento e na escrita hebraicas. Enquanto vivo, suas obras foram

\footnotetext{
Doutora em Teoria Literária e Literatura Comparada pela Universidade de São Paulo. Email: <nrozench@usp.br>.
} 
publicadas em oito volumes. Treze outros volumes, publicados postumamente, se somaram a eles. Mesmo não sendo hoje o escritor mais popular do país, é aquele a quem foi dedicado o maior número de obras críticas, em livros e artigos. Diversos dos seus textos foram adaptados para o teatro. Em português, há cinco volumes: os romances Uma história simples e Hóspede por uma noite, e as coletâneas de contos Novelas de Jerusalém, Contos de amor e Noivado e outros contos.

As mencionadas seis décadas de carreira de Agnon transcorreram em territórios e condições diversas e, como é de se supor, o autor absorveu destas vivências e circunstâncias. Os traços destas experiências muitas vezes somente frutificaram nas suas obras literárias tempos depois. Em sua Buczacz natal, cidadezinha então com maioria de população judaica, onde recebeu grande parte da educação do próprio pai que tinha formação rabínica mas se dedicava ao comércio de peles, teve acesso às diversas correntes judaicas: hassidismo e seus opositores, sionismo, ilustração, socialismo, anarquismo, sonhadores de diversos naipes, e usufruiu de todas. No campo literário geral, contou com o que era publicado em alemão, inclusive traduções de outras línguas. A influência da literatura escandinava ocorreu anos depois. Começou a escrever em hebraico e em ídiche já aos oito anos. Aos 18 anos passou a assessorar a edição do jornal hebraico local, um dos oito ou nove periódicos que publicaram as suas primeiras obras. Em 1907, aos vinte anos, atraído pelo Sionismo, distanciado de prática religiosa, decidiu estabelecer-se na Palestina, então parte do Império Otomano. Até aí, já havia publicado cerca de 70 textos nas duas línguas. No caminho, travou contato com escritores que o muniram de cartas de recomendação. Escolheu viver no bairro judaico de Nevê Tsédek na cidade portuária árabe de Jafa, junto a Tel Aviv, cidade que começaria a ser construída no ano seguinte. Jafa constituía o centro das atividades ligadas à colonização do país. Agnon logo tornou-se proeminente como jovem escritor. Pouco tempo depois publicou ali a sua primeira obra no país, o conto "Agunot" (Esposas acorrentadas ou abandonadas ou que estão no limbo), de cujo título extraiu aquele que se tornaria o seu sobrenome oficial, Agnon.

Agnon fez parte da Segunda Aliá, a segunda onda imigratória ao país, a mais importante de todas, que transcorreu de 1904 a 1914, e trouxe ao país aproximadamente 40 mil judeus provenientes em especial da Rússia. Foi com esta onda imigratória que se promoveu o estabelecimento do sistema coletivo de vinculação à terra - o kibutz, que atraiu a maioria dos recém-chegados, a definição do espírito do pioneiro - o halutz, a língua hebraica renovou-se, brotaram os jornais, literatura, partidos políticos, organização dos trabalhadores agrícolas. Esses imigrantes eram um grupo pequeno, mas ferozmente dedicado, cujos membros incluíam muitas das figuras fundadoras do futuro Estado de Israel. Estes pioneiros colocaram as bases que conduziriam o ishuv, a comunidade local, no caminho em direção a um estado independente. Muitos pioneiros não conseguiram se sobrepor às dificuldades encontradas e partiram.

Agnon não foi um pioneiro no sentido estrito do termo. Muitos imigrantes viveram nas cidades e Agnon foi um destes; viveu no meio da intelectualidade e ativistas de fala russa e pensamento marcado por aspectos da cultura daquele país; no breve período em que viveu então em Jerusalém travou contato com os diversos grupos religiosos, em parte diferentes daqueles que tinha conhecido na cidade natal.

Os contos mais antigos de Agnon são reelaborações artísticas de temas existentes em relatos folclóricos. Um dos temas que o atraíram desde o início foi o do erro fatal e suas consequências inevitáveis. Para se começar a entender a obra de Agnon, a menção do seu primeiro conto, "Agunot", publicado em 1908 no novo país, se justifica. O conto se inicia com uma imagem de ordem moral rompida. Deus é descrito tecendo um belo xale de orações dos fios da bondade amorosa das ações do povo de Israel. Mas às vezes ocorre um acidente, um fio se parte, o tecido começa a desfiar, ventos maus se infiltram e o fazem em pedaços. A imaginação de Agnon conduz os fatos para o espectro destruidor e não há como revogar suas 
consequências devastadoras. Em cada caso, os protagonistas são pegos em uma corrente irreversível de circunstâncias que os levam à ruína.

Agunot, plural de aguná, é um termo jurídico judaico que se refere a uma mulher casada cujo marido a abandona sem lhe conceder o divórcio, medida que é exercida com exclusividade pelo marido e que, naturalmente, a impede de se casar de novo. Em um modo que iria demonstrar características de sua imaginação, o jovem Agnon escreveu este conto como um comentário irônico sobre este mundo e esta ideia. "Agunot" é a história de um casamento que fracassou, contado em um compasso com uma lenda e na rica linguagem ornamentada da poesia bíblica. Dina, filha de um rico homem de Jerusalém, está noiva de Ezequiel, um prodígio rabínico, que é trazido da Polônia para ser seu marido. O casamento é arranjado pelo pai de Dina, mas cada um dos cônjuges ama uma outra pessoa. Ezequiel ama uma serviçal na Polônia e Dina se apaixona pelo artesão Ben-Uri que constrói uma arca para conter o rolo da Torá em homenagem à erudição do noivo e a ser colocada no local em que este se dedicará ao estudo em Jerusalém. Dina e Ezequiel se casam; seu casamento não é consumado; seu isolamento mútuo conduz ao divórcio, e Ezequiel retorna à Polônia.

Este tema de escolha pessoal e amor romântico frustrado por um édito paterno e da tradição, é antigo na literatura. Mas no contexto da experiência judaica do início do século XX, ele é particularmente potente como um símbolo de uma modernidade perturbadora.

Agnon vê a situação pelas lentes do século XX, enfatizando o alto custo psicológico e erótico da obediência à convenção e à autoridade. Outro traço modernista é a descrição de BenUri como um gênio da arte para quem a criação artística é uma forma de oração ou a substitui. Ele está tão envolvido com seu ofício que ignora Dina que, por sua vez, se exaspera com sua indiferença. Ele é desvinculado de relações humanas comuns pelas exigências de sua arte. Dina, enraivecida, lança o rico armário pela janela. Procurados depois que Dina confessa o seu pecado, o artesão e o resultado do seu artístico ofício não são mais encontrados.

Para que se entenda um pouco mais, Ben-Uri, o artesão, é referência ao personagem bíblico Betsalel Ben-Uri cuja missão foi construir o tabernáculo. A Bíblia o descreve como contendo o espírito divino e dotado com a sabedoria, discernimento ou conhecimento técnico, e o talento para toda espécie de ofício. (Êxodo, cap. 31: 1-6 e 35-39). Na Bíblia, criatividade é frequentemente um campo em que Deus está em conflito com os humanos, mas não é o caso de Betsalel. O significado do nome Betsalel, conforme o texto original - "na sombra ou à sombra de El" (na proteção de Deus) e Ben-Uri, "o filho de minha luz" - indica um relacionamento especial entre Deus e Betsalel. Na escrita de Agnon, a arte e, se quisermos, outras formas de criação como a literatura, é colocada ao nível do sublime. O tema do escritor e sua escritura é constante em suas obras.

Ainda a respeito de "Agunot": dado o local e a época em que foi escrito, verifica-se que ele retrata outro tipo de "casamento" fracassado: entre imigrantes judeus e a Terra de Israel. Ezequiel, que representa o melhor do judaísmo do leste europeu com seu pietismo, devoção e poder intelectual, não pode encontrar felicidade em Jerusalém.

Com o uso do midrash ${ }^{1}$, Agnon dá à sua narrativa uma dimensão cósmica, estabelecendo uma correlação significativa entre ação e destino humano e eleva uma simples história de amor a um comentário sobre a condição humana. Na mescla de engajamento e ambiguidade, Agnon estabeleceu um precedente seguido pela geração seguinte de romancistas israelenses. Com o título no plural, e mesmo Dina tendo recebido o divórcio, Agnon expõe o amplo espectro do conceito de almas no limbo.

Neste conto já se podia discernir muitos dos temas que iriam conturbar Agnon ao longo da sua vida e os princípios que governaram a sua técnica literária após a Primeira Guerra, ou seja, uma técnica de composição e um intuitivo domínio imaginativo da realidade. A

\footnotetext{
${ }^{1}$ Interpretação alegórica de um texto sagrado ou variações homiléticas e legendárias de temas bíblicos.
} 
ressonância midráshica dá corpo a muitos contos de Agnon, e o método midráshico de expansão homilética automaticamente o induz a pensar de modo simbólico. Agnon, o nome que em sequência ele adotou, poderia referir-se a "alguém que descreve ou acompanha almas em limbo".

Na sua obra posterior, Agnon não apresentou mais esta situação nos termos tradicionais de destino inexorável, mas colocou seus personagens no mesmo dilema de serem objeto de forças incompreensíveis sobre as quais eles não têm domínio.

No período de Jafa, ele publicou dezesseis contos.

Em busca de um ambiente cultural mais amplo e por influência do sociólogo Arthur Ruppin, ideólogo, ativista e um dos fundadores de Tel Aviv, Agnon partiu para Berlim em 1912. Ali desenvolveu sua escrita em um ambiente onde se concentrava um considerável número de autores e pesquisadores de temáticas da cultura judaica, como Martin Búber, Guershom Scholem e Chaim Nachman Bialik. Pela primeira vez, Agnon viveria em uma cidade que, apesar de possuir numerosa população judaica, não era uma cidade judaica, e onde se relacionaria abertamente com uma população diversa da sua. O longo período que Agnon viveu na Alemanha vem, incessantemente, recebido maior atenção dos estudiosos de sua obra em Israel e na Alemanha.

Apesar da Primeira Guerra, esse período de permanência na Alemanha, em que habitou diversas cidades, se estendeu até 1924 e isto foi benéfico para Agnon. Depois de gerações voltadas à aspiração de assimilação e germanização, começou a se mostrar no seio da intelligentsia judaica local uma tendência nítida de "Renascimento Judaico" que esteve em grande escala envolvida na ideia sionista. O prenunciador da onda neojudaica, já em 1901, foi o escritor e pensador Martin Búber, que ainda na primeira década do século passado publicou duas antologias de contos hassídicos editadas em alemão: suas publicações tiveram enorme repercussão e simbolizaram a busca de judeus alemães por uma tradição judaica que fosse considerada "autêntica", e a disponibilidade de agregar à sua a cultura dos judeus do Leste europeu, a dos Ostjuden, que até pouco antes eram vistos de modo crítico e menosprezado. Ao mesmo tempo, é preciso lembrar que a prática do hassidismo, movimento piedoso e místico judaico, quase não contava com adeptos na Alemanha. A tendência de retorno às fontes do judaísmo sobreviveu aos dias da Primeira Guerra e até teve um novo impulso no período Weimar no âmbito da literatura, poesia, artes plásticas, historiografia e folclore. Foi Martin Búber quem estabeleceu a definição histórico-formal deste novo fenômeno, denominando-o de Renascimento Judaico. A experiência do Renascimento foi uma expressão de último recurso de liberação do estado de assimilação espiritual dos judeus alemães para uma nova autoconsciência espiritual e vinculação criativa à língua hebraica em todos os seus registros e níveis. A organização prática das instituições educacionais judaicas absorveu o novo espírito e as mudanças que ocorreram no papel do Sionismo em suas diferentes interpretações. O conceito de Renascimento Judaico foi adaptado a diferentes direções e profundidades por parte da elite judaica alemã.

Búber se interessou pelo jovem escritor recém-chegado de Jafa, pois viu nele, como ser humano e como artista, o portador autêntico do judaísmo do Leste europeu que ele queria incutir nos judeus da Alemanha. Búber estimulou a tradução para o alemão dos contos de Agnon que refletiam, mais do que tudo, a sua ideologia cultural. Junto com Agnon, Búber embrenhou-se em um projeto ambicioso de coletar a literatura hassídica, e somente devido ao incêndio que ocorreu na casa de Agnon, em 1924, o projeto foi interrompido. Em uma famosa, embora curta, nota de 1916 intitulada "A respeito de Agnon", Búber esboça o retrato do escritor, adequandoo de forma categórica ao horizonte de expectativas dos simpatizantes do conceito do "Renascimento Judaico": " ... Ele deve ser o escritor e o documentador da vida judaica, para aqueles que agora já estão agonizando e mudando, mas também para os outros que estão se formando e ainda não são conhecidos.” (BÚBER, 1916 apud LAOR, 2001, 2011) 
Búber foi seguido por Guershom Scholem, que se tornaria famoso pelos estudos da mística judaica, que igualmente se empenhou na tradução de alguns dos contos de Agnon para o alemão, movido pelo sentimento de que as histórias de Agnon, especialmente aquelas ligadas ao mundo dos judeus poloneses (nestas alturas, Buczacz e o universo judaico de Agnon eram território polonês), eram um componente importante da concepção judaica que ele e seus contemporâneos tentavam criar para si mesmos. O mecenas e editor Zalman Schocken encarregou-se da publicação e divulgação das obras de Agnon.

Na Alemanha, Agnon trabalhou na elaboração do gênero historiográfico legendário, lendas polidas e etnográficas sobre os primórdios do assentamento judaico na Polônia, além de contos de amor realistas. Os contos com base folclórica ambientam-se nas comunidades de judeus piedosos da Galícia ou da antiga comunidade judaica de Jerusalém. Vários deles foram publicados primeiramente em tradução ao alemão e somente mais tarde em hebraico. Os 14 contos que compõem o conjunto Polônia: lendas, que lidaram com a vida judaica no Leste europeu nas gerações anteriores, foram sintomáticos de todo o período e firmaram a imagem do artista na mente dos leitores da Alemanha. No meio social narrado, que era feudal, os judeus foram protegidos dos proprietários rurais ou clérigos hostis por reis benevolentes. Agnon conseguiu criar a imagem de uma comunidade típica. Deve-se notar que a Galícia e seus modos folclóricos judaicos peculiares se tornam o ponto focal principal da imaginação de Agnon precisamente quando ele estava vivendo na Alemanha. A comunidade judaica é inquestionavelmente temente a Deus, um fato básico que proporciona ao autor o mundo consumado de costumes e valores e que lhe permite deslizar de modo natural para dentro de um universo de fantasia e mistério. Agnon desenvolveu um artifício poético que transportou os relatos míticos de contos que parecem ser românticos e repletos de esplendor para contos que revelam seu potencial crítico dos judeus poloneses que se apaixonaram por sua diáspora.

O desenvolvimento literário de Agnon nos anos 20 expõe a luta do autor que começou a passar do conto ao romance e mais especificamente dos fragmentos da experiência do conto folclórico para um mito abrangente do primeiro romance que iria publicar, Hachnassat kalá (Casar uma noiva). Durante o período alemão, o romance esteve tomando forma. A primeira versão surgiu em 1919 na revista americana Miklat. Várias histórias que depois foram incluídas na segunda versão do romance surgiram na década de 20. Em 1931 foi publicado o romance inteiro e, em 1953, surgiu uma nova edição expandida. Em Hachnassat kalá o relato folclórico respira o ar da ingenuidade e engenho enquanto a estrutura do romance implica em sofisticação e sutileza artística.

Trata-se de um romance épico burlesco com uma história-moldura contendo dezenas de relatos hassídicos ${ }^{2}$. A narrativa é dupla: ingênua, segundo o modelo de relatos folclóricos clássicos, e ardilosamente sofisticada como uma obra moderna. O romance parodia o relato folclórico hassídico mas o faz delicadamente: censura sem acrimônia sempre mantendo um ar de reverência pelo velho mundo. A história é bastante sutil para apoiar leituras divergentes e isto é claramente pertinente à habilidade de Agnon.

Ambientada no início do século XIX, a trama é em parte uma busca e em parte comédia de erros, afastando-se de modo progressivo de seu tom inicial de realismo. Emoldura a história frouxamente em torno de uma figura de um hassid paupérrimo e devoto, Reb Yudel de Brody, e seu vagar constante na Galícia procurando noivos e dotes para as três filhas; é uma figura passiva que sempre aceita os eventos do mundo, mesmos os infaustos, como sendo préordenados e cujas intenções são abençoadas por Deus. Ele é finalmente salvo por um milagre surpreendente de um deus ex-machina. O protagonista de Agnon, Reb Yudel, confia no sistema divino de um modo que o torna uma figura sólida e estável, com uma identidade resiliente,

\footnotetext{
${ }^{2}$ Hassidismo - movimento que prega a busca do êxtase nas relações com Deus e suas criações no mundo terreno.
} 
apesar do fato da troca de identidades ser um dos temas principais do romance apresentado dentro de uma comédia de erros.

À parte as referências ocasionais ao Rebe de $\mathrm{Apt}^{3}$, estas histórias não entram na categoria de relatos hagiográficos dos tsadikim $^{4}$ : são mais relatos folclóricos de judeus pobres e comuns da Galícia, muitos dos quais, naturalmente, eram hassídicos. O tratamento das histórias de milagres por Agnon é irônico, uma vez que o que parece sobrenatural geralmente acaba sendo coincidência. Também é de se notar que mulheres - a esposa de Yudl e as filhas têm um papel nisto mais ativo que o passivo Yudl, uma divisão de gênero comum na ficção de Agnon. Em um estilo que se tornaria famoso em seus romances e contos subsequentes, o relato de Agnon do hassid errante combina um retrato amoroso e nostálgico de um mundo judaico de um século antes com relatos de horror violento ou de sátira ardilosa.

$\mathrm{Na}$ Alemanha, Agnon chegou à maturidade artística, revisando com rigor os seus trabalhos anteriores. Absteve-se completamente de reagir por escrito ao ambiente imediato e à realidade do seu tempo. Enquanto viveu na Alemanha, foi evidente a tendência de expandir e aprofundar a representação do antigo mundo do Leste europeu em seus escritos com os mencionados Polônia: lendas, inspirados pelo espírito do Retorno ao Judaísmo e seu encorajamento.

O incêndio da casa de Agnon, que destruiu tanto os seus manuscritos como a rica biblioteca de quatro mil volumes voltada ao judaísmo tradicional e ao popular que acumulara da vida judaica nos séculos anteriores, fê-lo decidir rapidamente que chegara a hora de retornar à Palestina, então sob Mandato Britânico. Seu amplo romance autobiográfico que aparentemente estava pronto para ser publicado, virou cinza. Agnon jamais voltou a escrevêlo. O retorno foi também a ocasião da volta à prática da vida judaica tradicional deixada de lado desde que chegara ao país pela primeira vez. Estabeleceu-se em Jerusalém.

A partir de 1932, quando a primeira coleção de suas obras já tinha sido completada, Agnon começou a publicar Sêfer hamaassim (O livro dos feitos), uma coleção composta de contos experimentais não realistas que acabam com as dimensões de tempo e lugar, em que sequência lógica e causalidade parecem estar suspensas e revela o mundo instável e inconsciente do crente transmitindo um sentido de ansiedade. Na mesma época começaram a se cristalizar os romances.

Tendo realizado rápidas e raras visitas à sua cidade natal, ele publicou no romance Oreach natá lalun ${ }^{5}$ (Hóspede por uma noite), o seu confronto pessoal com a morte interna do judaísmo do Leste europeu que já se prenunciava há tempo. O leitor deste livro de 1939 encontra uma cidade que está afundando, com seus poucos habitantes judeus vivendo entre as ruínas, em luto e pobreza. A antiga casa de estudos, a cidadela espiritual do lugar, está prestes a ser esvaziada por completo, alguns poucos livros jazem nas prateleiras e tudo está negligenciado. A população judaica restante das cidadezinhas foi eliminada na II Guerra. Agnon imortalizou a sua cidade em cerca de 160 contos.

Somaram-se a estas obras, nos anos 30 e 40, contos de naipes diversos: lendas, contos de amor, contos modernistas, contos realistas. As décadas de 50 e 60 foram marcadas também por crônicas sobre sua cidade natal, contos modernos mais complexos.

De meados dos anos 30 em diante os múltiplos significados dos textos de Agnon tornamse mais evidentes.

\footnotetext{
${ }^{3}$ Rabino Avraham Yehoshua Heschel, rabino de Apt (Opatów) 1748-1815, fundador da dinastia hassídica AptMejbij-Zinkover. O estudioso da literatura, Meír Bussak, recompõe a origem do personagem de Agnon e do relato de busca de noivo e dote conforme a brochura Sichot Yekarim datada provavelmente de 1915. (BUSSAK, 19881989). O mencionado rabino e o feito são citados na brochura utilizada.

${ }^{4}$ Plural de $t$ sadik (hebraico). Pessoa considerada santa pelos judeus ultraortodoxos.

${ }^{5}$ Versão brasileira: Hóspede por uma noite. Trad. Zipora Rubinstein, São Paulo, Perspectiva, 2014.
} 
Mesmo depois de seu retorno a Israel, a Alemanha não ocupou de imediato um lugar importante em sua agenda literária. Todavia, ocorreram mudanças nos anos seguintes à Segunda Guerra Mundial. Depois da Guerra, depois do Holocausto, depois que o mundo judaico-alemão deixou de existir, Agnon começou a escrever contos e novelas centrados na Alemanha da Primeira Guerra Mundial ou sobre judeus provenientes da Alemanha em Israel e seu destino; foi uma ficção que combinou descrição detalhada da experiência do interior alemão durante a Guerra com uma reflexão profunda do mundo social e espiritual de judeus alemães com os quais se familiarizara durante os anos em que viveu ali e que em Jerusalém compu seram uma imagem vívida daqueles que, sobrevivendo, continuaram profundamente vinculados à língua e à cultura alemãs e ao judaísmo que tinham praticado anteriormente e que carregaram a frustração pelo desmoronamento de tudo o que esperavam de suas existências. Segundo Gershon Shaked, "quando contemplou o judaísmo alemão, Agnon não encontrou uma sociedade que se sobressaiu por uma revolução, mas um mundo vazio de tradição". (SHAKED, 1989, p. 81)

A presença do mundo e da cultura alemães na obra de Agnon cristalizou-se a partir de uma perspectiva de longo alcance em alguns romances. Ad hena (Até aqui), publicado em 1952 transporta o leitor para a Alemanha de 1916-1918, assim como a trama de Behanuto shel Mar Lublin (Na loja do Sr. Lublin), obra escrita provavelmente na década de 1960 e publicada postumamente em 1975, que se desenrola em Leipzig no auge da Primeira Guerra. Neste romance, Agnon retrata um complexo de tensões na sociedade alemã entre as classes e personalidades conectadas com a guerra, criando uma analogia entre as mudanças que ocorreram no mundo judaico pré-moderno e as mudanças no mundo alemão e o seu significado. O universo dos judeus alemães é contrastado com o dos judeus provenientes do Leste europeu e, com mais intensidade, com o universo alemão que o protagonista, Sr. Lublin, tenta com todo o empenho abraçar. Questões de assimilação e dos remanescentes da identidade judaica são abordadas sob vários ângulos.

Diversas das obras publicadas postumamente são consideradas as melhores produções de Agnon. O complexo romance Shira é, segundo os críticos, um dos mais destacados ou o mais destacado dos seus livros. Ele contém quase tudo o que seus romances anteriores abrangeram e mais. Alguns veem nele a visão final de Agnon sobre o universo judaico-alemão.

Agnon ocupou-se do livro Shira por mais de 25 anos; publicou vários de seus capítulos coletados nas três das quatro partes da obra, em 1948, 1952 e 1966 em suplementos de datas festivas do jornal Haaretz, despertando imenso interesse, mas o arquivou em seguida. Tanto as temáticas do livro quanto os motivos que levaram o autor a bloqueá-lo até o fim da vida, foram e são motivos de muita especulação. Razões poéticas podem ter se somado a objeções de leitores vinculados a diferentes pensamentos ideológicos vigentes no país, de militantes e de pacifistas, diante principalmente dos violentos confrontos e ataques árabes à população judaica da Palestina do período em que a obra se situou e presentes no livro, das severas restrições dos mandatários britânicos, da dificuldade em obter certificados de entrada no país que garantiriam a sobrevivência. Foram fatores que o ajudaram provavelmente a entender que Shira era uma obra anarquista em que se degradavam convenções e eram violadas tradições.

Em Shira, o artista maduro conseguiu observar, do ápice de sua idade, os meandros e nuances da existência humana, a partir de uma sensibilidade incomum e uma profunda compreensão psicológica, e por meio de uma linguagem transparente e exata. Agnon somente autorizou a publicação do livro - incompleto - e, então, não devidamente organizado, no leito de morte. Isto resultou em um livro potente, mesmo que inacabado, que passou por três reorganizações e ampliações diferentes (1971, 74 e 78 e edição corrigida em 1999) com dimensões diversas, pela Editora Schoken, com 560 páginas no final.

No pano de fundo da sofrida Jerusalém dos anos trinta com medidas restritivas do mandatário britânico e graves distúrbios promovidos pela população árabe, somados aos 
sentimentos pós-guerra do autor que presenciara a destruição da maior parte do judaísmo europeu, Shira aborda principalmente o mundo espiritual alemão do professor de história, Manfred Herbst, especializado no estudo de Bizâncio e dos Patriarcas da Igreja, que, nos anos 20 do século passado imigrou da Alemanha para Jerusalém quando da criação da Universidade Hebraica e nela, a exemplo de vários outros conterrâneos, lecionou e realizou as suas pesquisas. $\mathrm{O}$ número de professores provenientes da Alemanha na universidade foi marcante.

A partir de uma perspectiva histórica de Herbst, sua personalidade e campo de atuação, pode-se estabelecer a referência de Agnon ao mundo alemão teutônico, oriental e europeu moderno como substituto inadequado da cultura grega clássica. E mais, o sentido da história e o que ela nos ensina é questionável, como o expõe Robert Alter, que escreveu o posfácio da última edição americana do livro,

Sendo a esfera dos objetos do conhecimento a história ... será que estas pesquisas históricas nos dizem algo de essencial sobre as forças que estão a levar a nação alemã a fuzilar, a matar com gás e a incinerar milhões de homens, mulheres e crianças? Os perpetradores europeus desses horrores são afinal, ao menos em parte, produtos da mesma cultura acadêmica produzida por Herbst e seus colegas. (ALTER, 2013, p. 576)

Shira é também o esforço culminante de Agnon de articular a sua visão do papel da arte na realidade humana.

Herbst, habitualmente passivo tanto na carreira como na vida pessoal, na meia-idade (o sobrenome Herbst significa outono), se encontra em crise profissional e pessoal. Seu trabalho como professor de história de repente lhe parece trivial e estéril, sente bloqueios para escrever, o que impede sua ascensão na escala profissional acadêmica, enquanto seu relacionamento com a esposa Henrietta também chega a um beco sem saída. É nessas circunstâncias, quando a esposa dá à luz à terceira filha, temporã e não prevista, que ele conhece e é seduzido por uma enfermeira do hospital, que não prima pela beleza ou pela intelectualidade, masculinizada, ainda assim sensual, com o nome incomum de Shira, nome que significa poesia. Com este nome, arte e eros vinculam-se na concepção agnoniana.

Incapaz de dar continuidade à pesquisa, Herbst descobre que um encontro carnal efêmero com um objeto de desejo improvável abre novas perspectivas e o impele, por modos dos quais ele mal tem consciência, a fazer algo radicalmente diferente em sua vida. Propõe-se, então, a escrever uma tragédia sobre costumes rituais de sepultamento dos pobres de Bizâncio. A experiência de Herbst com a ambiguidade radical de eros no seu envolvimento com Shira/poesia o leva a sentir que a arte, diversamente da pesquisa histórica, tem a capacidade de produzir um doloroso autoconhecimento. A obra também não vai adiante. O relacionamento erótico com Shira, sem amor, o livra de sua rotina diária e lhe dá esperança de renovação que, todavia, é limitada.

Ante o bloqueio de Herbst, Dan Miron assevera que

O ser humano nos escritos de Agnon é incapaz de superar os conflitos fundamentais que determinam a sua posição no mundo em todos os seus aspectos ou camadas: biológico, social, sexual, emocional, racional, nacional, religioso. Qualquer tentativa de superar esses conflitos termina em Agnon em fracasso de um tipo ou outro: desaparecimento, como a do artista Ben Uri em "Agunot" ou de Shira, ou terrível morte santa, pagã ou, pior ainda, não-santa. No caso mais moderado, o fracasso significa submeter-se a uma vida de trabalho cotidiano, abandonando os sonhos da juventude, e afundar na mediocridade e falta de autoconsciência. Acima de todos estes, porém, paira 
uma visão sombria irônico-trágica de redenção que nunca realmente se materializará, pelo menos não no nosso tempo, não neste mundo, não na terra como a conhecemos. (MIRON, 30.05.2017)

Assim são os personagens de Agnon. Segundo comenta Jeffrey Saks, "há um paradoxo na criação de Agnon. Todos os seus grandes personagens encontram-se entre crime e consequência, pecado e culpa, ação e responsabilidade e sempre entre tradição e modernidade" (SAKS, 15.04.2013, p. 146, 147). Herbst é um deles.

Shira desaparece (em uma das versões do livro) mas a tortura do desejo e esperança do professor não recuam.

A narrativa longa e digressiva abrange o corpo acadêmico da época. Temas como o amor, o conceito de vida como uma doença (Shira desenvolve sinais da lepra), com arte como doença destruidora, se destacam. É uma narrativa plena de ironia e sátira e até mesmo zombaria. Um dos retratos mais contundentes da época exposta, Shira é um romance repleto de contos de imigrantes, com lances filosóficos frequentemente irônicos e com as reflexões, sonhos e fantasias sadomasoquistas de Herbst, enquanto ele transpõe a decadência e o esplendor bizantino para um mundo que é tomado pelo horror genocida.

Já no primeiro conto mencionado acima - "Agunot", o papel da arte era percebido. Para Agnon, é o artista que está preparado para dar o perigoso último passo na floresta onde as contradições finais devem ser confrontadas, onde ele deve se colocar além do limite dos valores recebidos. Em Shira, romance onde aos eventos subjaz uma intensa narrativa sobre "eros e arte, arte e doença, acentua-se o conceito de que a arte existe para ser o veículo de uma ordem de conhecimento mais profunda, mais perigosa e dolorosa do que poderia ser obtida por qualquer instituição de aprendizado. religiosa ou secular”. (ALTER, 2013, p. 585)

Se foram esses os entraves que bloquearam a publicação de Shira, a decisão final de, ainda assim, trazer o livro à luz, serve tanto para reptar o judaísmo alemão pelas suas posições, particularmente em relação ao judaísmo, como assinalar, em definitivo, o que Agnon formulou de modo brilhante sobre a arte, moto para autores e leitores que se seguiram, beneficiários agradecidos que somos.

\section{Referências}

ALTER, Robert. Posfácio de AGNON, S. Y.. Shira. Trad.: Zeva Shapiro. New Milford, The Toby Press, 2013, p. 576, 585. Disponível em <https://books.google.com.br/books?id=Dbhw tE7bb3MC\&pg=PA584\&lpg=PA584\&dq=SHIRA+-+AGNON\&source=bl\&ots=VzD492Nky V\&sig=UGFUUHP4_PV1bcvjU0gTe0RMo5M\&hl=pt-BR\&sa=X\&ved=2ahUKEwiJzsqF7L _dAhWGH5AKHXqKAlc4ChDoATAHegQIAxAB\#v=onepage \&q=SHIRA\%20-20AGNON $\& \mathrm{f}=$ false $>$. Consultado em 05/05/2020.

BÚBER, Martin, “Al Agnon” (A respeito de Agnon) Der Jude, 1916, apud LAOR, Dan. "Agnon beguermania" (Agnon na Alemanha). In Haaretz 26.07.2001, atualizado em 15.08.2011. Disponível em <https://www.haaretz.co.il/misc/1.720665>. Consultado em 05/05/2020.

BUSSAK, Meír. Limkorot yetsirato shel Shai Agnon (A respeito das fontes da obra de Shai Agnon). Daat. Mabua 21, 1988-1989. Disponível em <http://www.daat.ac.il/daat/kitveyet/ mabua/lemakor-2.htm>. Consultado em 05/05/2020. 
MIRON, Dan. "Adayn poem halev haagnoni” (Ainda palpita o coração agnoniano). In Haaretz, 30.05.2017. Disponível em <https://www.haaretz.co.il/literature/.premium-1.4136949>. Consultado em 05/05/2020.

SAKS, Jeffrey. Agnon's Shaking Bridge and the Theology of Culture. Orthodox Forum YUTorah on Line. 15.04.2013, p. 146, 147. Disponível em <https://www.yutorah.org/lectures/lecture.cfm/898824/rabbi-jeffrey-saks/agnon-s-shakingbridge-and-the-theology-of-culture/>. Consultado em 05/05/2020.

SHAKED, Gershon. Shmuel Yosef Agnon A revolutionary Traditionalist. Nova York, New York University Press, 1989, p. 81. 